Article

\title{
Research on Single-Phase PWM Converter with Reverse Conducting IGBT Based on Loss Threshold Desaturation Control
}

\author{
Xianjin Huang * (D), Dengwei Chang, Chao Ling and Trillion Q. Zheng \\ School of Electrical Engineering, Beijing Jiaotong University, No. 3 Shangyuancun, Beijing 100044, China; \\ sanyeh@163.com (D.C.); thesuese@163.com (C.L.); tqzheng@bjtu.edu.cn (T.Q.Z.) \\ * Correspondence: xjhuang@bjtu.edu.cn; Tel.: +86-136-8358-7910
}

Received: 15 September 2017; Accepted: 5 November 2017; Published: 12 November 2017

\begin{abstract}
In the application of vehicle power supply and distributed power generation, there are strict requirements for the pulse width modulation (PWM) converter regarding power density and reliability. When compared with the conventional insulated gate bipolar transistor (IGBT) module, the Reverse Conducting-Insulated Gate Bipolar Transistor (RC-IGBT) with the same package has a lower thermal resistance and higher current tolerance. By applying the gate desaturation control, the reverse recovery loss of the RC-IGBT diode may be reduced. In this paper, a loss threshold desaturation control method is studied to improve the output characteristics of the single-phase PWM converter with a low switching frequency. The gate desaturation control characteristics of the RC-IGBT's diode are studied. A proper current limit is set to avoid the ineffective infliction of the desaturation pulse, while the bridge arm current crosses zero. The expectation of optimized loss decrease is obtained, and the better performance for the RC-IGBTs of the single-phase PWM converter is achieved through the optimized desaturation pulse distribution. Finally, the improved predictive current control algorithm that is applied to the PWM converter with RC-IGBTs is simulated, and is operated and tested on the scaled reduced power platform. The results prove that the gate desaturation control with the improved predictive current algorithm may effectively improve the RC-IGBT's characteristics, and realize the stable output of the PWM converter.
\end{abstract}

Keywords: RC-IGBT; low switching frequency; PWM converter; diode desaturation; loss threshold control

\section{Introduction}

The main feature of the pulse width modulation (PWM) converter is ensuring the high power factor and AC side sine wave current control on the target of the output DC voltage, as well as on the bidirectional power transmission. With the development of power semiconductor devices, the improvement of modeling and control strategy and sensing technology, the working performance of PWM converters is constantly improving. Electric rail transportation, uninterruptible power system (UPS), and a distributed power generation that is based on wind and solar energy storage have higher requirements on the power density, working temperature, cycle life, and reliability. The current research on PWM converters mainly concentrates on three aspects: new circuit topology, universality of the converter mathematical model, and control strategy [1-5]. Ref. [6] adopted a hybrid clamped five-level topology to successfully solve the non-uniformity of the DC capacitor voltage of the three-phase PWM converter. Ref. [7] gave a mathematical model of a single-phase PWM converter based on the unipolar modulation in the stationary coordinate and d-q coordinate. Refs. [8,9] proposed the predictive current control to achieve zero steady-state error of the grid current, and greatly reduce its harmonic content. In addition, due to the fact that power devices are the cornerstone of the converter system, there have also been researches 
performed on electrical stress, temperature loss, and reliability of PWM converters. Ref. [10] explained that the Reverse Conducting-Insulated Gate Bipolar Transistor (RC-IGBT) has a uniform current density and temperature distribution uniformity in insulated gate bipolar transistor (IGBT) or diode mode, and greatly improves the reliability of the equipment. Ref. [11] effectively realized the two-way flow of the point current, and improved the efficiency of the inverter by introducing reverse blocking IGBT (RB-IGBT) to the T-type three-level inverter.

Due to their strong electrical characteristics and gate control capability, IGBT devices have now fully occupied $500 \mathrm{~Hz}-100 \mathrm{kHz}$ high voltage and high power applications. In the past 30 years, IGBT devices have been constantly updated in terms of structure results, leading to the continuous improvement in performance. The structures of the devices have undergone a technical revolution of non-punch through (NPT), field stop (FS), and so on, in which, from the earliest punch through (PT) type, the surface structure developed from a plane grid to a groove gate structure, and various new structures and derivative devices emerged in an endless stream [12]. As a result, the resistance junction temperature has become increasingly higher, the device loss is reducing, the switching speed is becoming faster, and the voltage level and current capacity are improving significantly, gradually approaching the material performance limit. Commercial IGBT single modules have reached the $6500 \mathrm{~V} / 1000 \mathrm{~A}$ and $4500 \mathrm{~V} / 3000$ A levels [13]. Reverse conducting IGBT allows for IGBT chips and freewheeling diode chips to integrate in the same cellular chip within the internal structure and function design, which improves the thermal efficiency of the chip and reduces the parasitic parameters of chip connection. It has a higher current tolerance than that of the traditional IGBT with the same package. The RC-IGBT integrated diode is controlled by desaturation pulse, which can significantly optimize the diode reverse recovery characteristic. The reverse conducting IGBT device is applied to the locomotive traction converter, which has a positive effect on reducing the number of devices and improving the performance of the temperature rise and heat dissipation [14,15].

In this paper, the driving and loss characteristics of RC-IGBT are introduced, and the improved predictive control method of RC-IGBT for single-phase PWM rectifier is studied. By setting the desaturation pulse control sequence of four switch devices in full bridge circuit, the diode desaturation control is realized to reduce reverse recovery loss. Because the inductor current may be zero crossing repeatedly and the small current detection may be error in the practical operation of single-phase PWM rectifier, it can cause the desaturation pulse repeated application, the time overlap, logic confusion, and other problems at the case of the criterion of the direction of the inductor current. A loss reduction threshold desaturation control method for RC-IGBT single-phase PWM rectifier is proposed. The threshold value of the current is determined by the threshold of loss variation in order to judge the application of the desaturation pulse. The loss of threshold desaturation control of RC-IGBT PWM rectifier is simulated by simulation, and the system loss is verified by analyzing and comparing the system loss with different threshold values. Finally, the experiment is carried out on a low power experimental platform, and the results also verify the correctness of the scheme.

\section{Control Characteristics of RC-IGBT PWM Converter}

\subsection{Driving and Loss Characteristics of RC-IGBT}

As shown in Figure 1, RC-IGBT allows the free-wheeling diode (FWD) and IGBT to be successfully integrated into silicon, by partly replacing the P-Collector (p-doped collector) with $\mathrm{N}$-Collector (n-doped collector) [16,17]. 


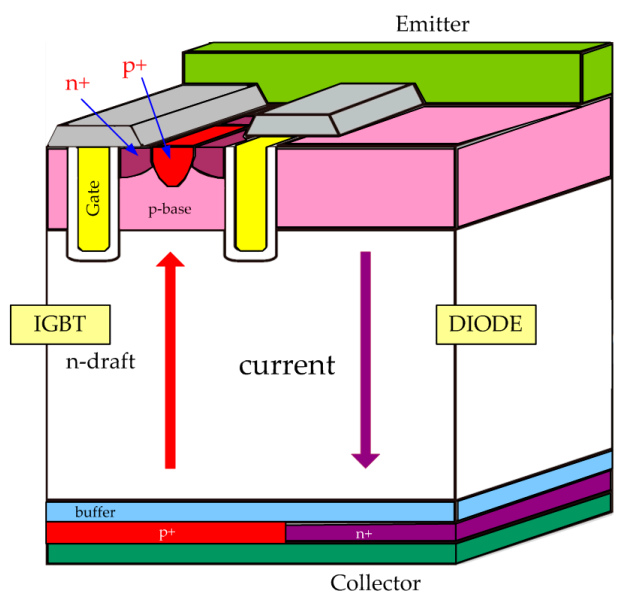

(a)

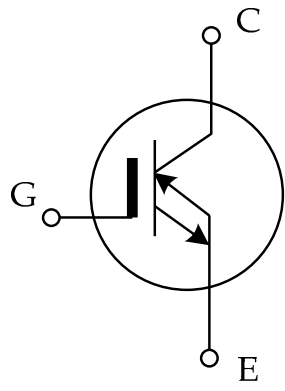

(b)

Figure 1. The diagram of Reverse Conducting-Insulated Gate Bipolar Transistor (RC-IGBT): (a) The internal structure; (b) the electrical symbol.

The operating characteristics of the RC-IGBT integrated diode are affected by the gate voltage, and the application of the gate voltage can change the flowing path and the recombination process of the carriers. The gate pulse voltage can affect the forward voltage drop of the integrated diode in RC-IGBT. As shown in Figure 2, the V-I characteristic curves of the integrated diode at $25^{\circ} \mathrm{C}$ and $125^{\circ} \mathrm{C}$ working temperatures are given for different gate voltages. The arrow in the figure shows that the gate voltages are $-15 \mathrm{~V}, 0 \mathrm{~V}$, and $15 \mathrm{~V}$, respectively. The greater the gate voltage, the higher the forward voltage drop across the same current level will be. In the two level PWM control, driving signal of the conventional IGBT was not considering the working state of the diode; otherwise, in the application of driving RC-IGBT, the diode conduction state should be detected to impose the low level gate voltage on the RC-IGBT for the aim of reducing the diode conduction loss $[18,19]$.

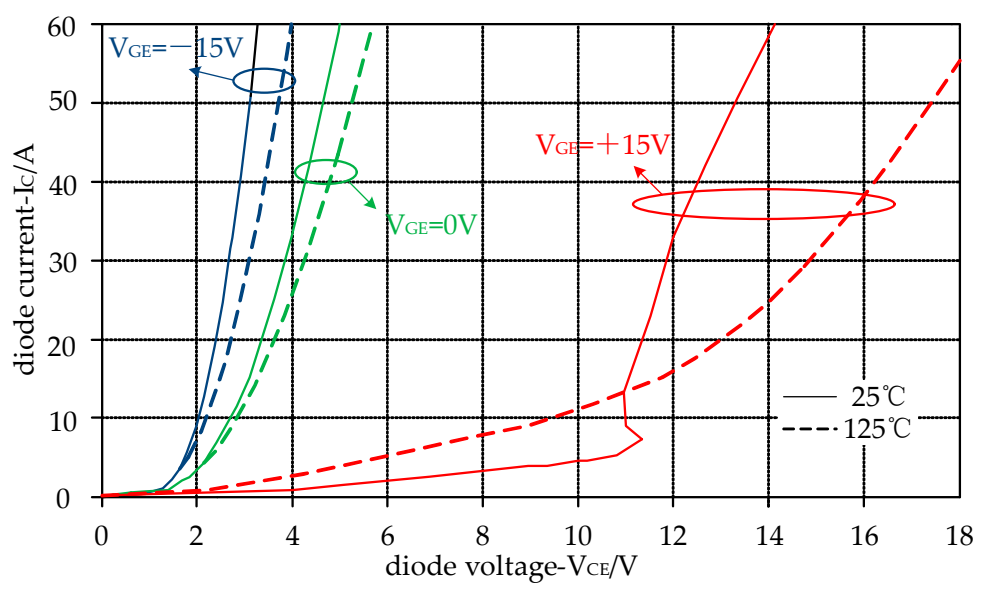

Figure 2. Static characteristic of RC-IGBT in the diode mode [20].

The low level gate voltage applied to the diode mode of the RC-IGBT could maintain the low diode conduction voltage drop, while the high level gate voltage could provide additional compound carriers for the diode reverse recovery to reduce the reverse recovery current. Before the reverse recovery process of the diode, a high level pulse is applied to desaturating the saturated diode temporarily. This pulse setting method is called the RC-IGBT diode desaturation control (RCDC). The desaturation pulse control is based on several key factors, such as the imposed pulse time, the amplitude of the pulse voltage, the pulse duration, the pulse turn-off time, and lock time. Ref. [20] studied the relationship 
between the single RC-IGBT desaturation pulse control and the device loss (including IGBT loss, diode loss, steady state loss, dynamic loss, and total loss). Our research in this paper is based on the fact that the proper desaturation pulse control has been selected on the single RC-IGBT. In a switching process of RC-IGBT, the desaturation pulse control can achieve better loss suppression.

Figure $3 \mathrm{~b}$ shows the sequential logic of the desaturation pulse $\mathrm{U}_{\text {ge-T1 }}^{\prime}$. The $\mathrm{T}_{1}$ turns off at the time $t_{0}$, the diode starts to be free-wheeling, the order of the $T_{2}$ turning on is execute at the time $t_{1}$, the desaturation pulse starts to be applied to the $T_{1}$ at the time $t_{2}$, it stops being applied to the $T_{1}$ at the time $t_{3}$, and the $T_{2}$ turns on actually at the time $t_{4}$. Because the time of turning on of the $T_{2}$ cannot be predicted in advance, the gate level pulse signal of $T_{2}$ is delayed, and the delay time is $t_{\text {delay }}$. The $t_{\text {free }}$ is the system processing time, the $t_{\text {desat }}$ is the desaturation pulse width, and the $t_{\text {lock }}$ is the dead time. Similarly, when the load current $\mathrm{I}_{\mathrm{L}}$ is reverse (outflow node), it is necessary to detect the forward conduction time of the $\mathrm{T}_{1}$, and to also apply the desaturation pulse to the $\mathrm{T}_{2}[21,22]$.

The values of the above time have the following relationships:

$$
t_{\text {delay }}=t_{\text {free }}+t_{\text {desat }}+t_{\text {lock }}
$$

$t_{\text {delay }}$ is determined by the three latter values.
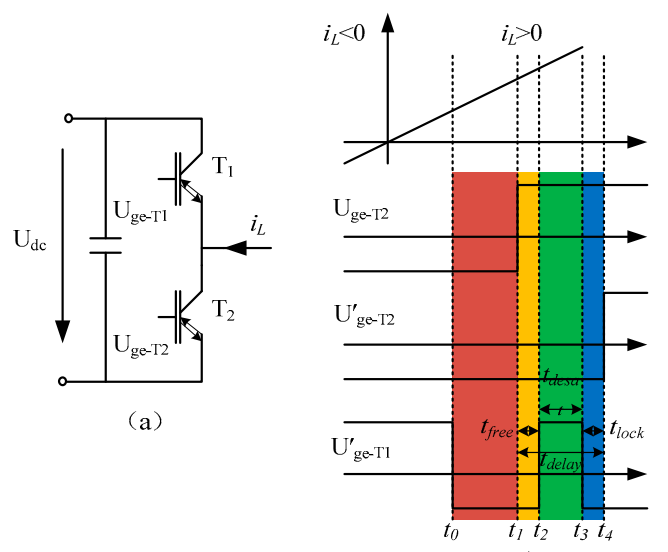

(b)

Figure 3. Desaturation pulse control of RC-IGBT in half bridge: (a) The structure of RC-IGBT in half bridge; (b) The logic of desaturation pulse control.

The loss of IGBT converter is mostly obtained by integrating the voltage and current of the actual circuit, and then obtained according to the V-I curve of the device parameter manual [23]. Figure 4 shows the current and switch status on the rectify operation of single-phase PWM rectifier. The total loss of all the devices in the half modulation period could be calculated based on the working status.

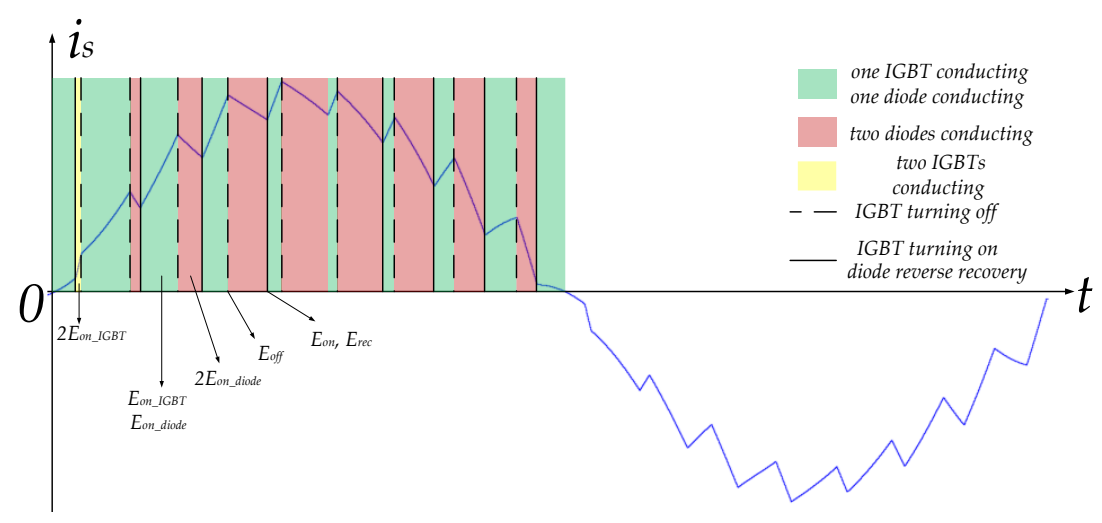

Figure 4. Loss analysis of the single phase PWM rectifier during a modulation period. 
The green region corresponding to one IGBT conduction loss and one diode conduction loss, the red region corresponding to the conduction loss of two diodes, and the yellow region is corresponding to the conduction loss of two IGBTs. The dashed area corresponding to the loss of the IGBT turning off, and the solid line region is corresponding to the IGBT turn-on loss and diode reverse recovery loss.

In the half modulation cycle, IGBT conduction loss, IGBT turn-on loss, IGBT turn-off loss, diode conduction loss, and diode reverse recovery loss could be written as follows:

$$
\begin{gathered}
E_{\text {con_IGBT_half }}=\sum_{i=1}^{m+1}\left\{V_{C E}\left[I_{C}\left(t_{2 i-1}\right)\right] \cdot I_{C}\left(t_{2 i-1}\right) \cdot T_{T_{-} 2 i-1}\right\}+2 V_{C E}\left[I_{C}\left(t_{2}\right)\right] \cdot I_{C}\left(t_{2}\right) \cdot T_{T_{-} 2} \\
E_{\text {on_half }}=\sum_{i=2}^{m}\left\{E_{o n}\left[I_{C_{-} \text {on }}\left(t_{2 i}\right)\right]\right\}+E_{\text {on }}\left[I_{C_{-} \text {on }}\left(t_{1}\right)\right] \\
E_{\text {off }} \text { half } \\
E_{\text {on_diode_half }}=\sum_{i=2}^{m}\left\{E_{\text {off }}\left[I_{C_{-} \text {off }}\left(t_{2 i-1}\right)\right]\right\}+E_{\text {off }}\left[I_{C_{-} \text {off }}\left(t_{2}\right)\right] \\
\sum_{i=1}^{m+1}\left\{V_{F}\left[I_{F 1}\left(t_{2 i-1}\right)\right] \cdot I_{F}\left(t_{2 i-1}\right) \cdot T_{D_{-} 2 i-1}\right\}+2 \sum_{i=2}^{m}\left\{V_{F}\left[I_{F 1}\left(t_{2 i}\right)\right] \cdot I_{F}\left(t_{2 i}\right) \cdot T_{D_{-} 2 i}\right\} \\
E_{\text {rec_ half }}=\sum_{i=2}^{m}\left\{E_{\text {rec }}\left[I_{C_{-} \text {on }}\left(t_{2 i}\right)\right]\right\}+E_{\text {rec }}\left[I_{C_{-} \text {on }}\left(t_{1}\right)\right]
\end{gathered}
$$

The total loss during a modulation cycle:

$$
E_{\text {tot }}=2\left(E_{\text {con_ IGBT_half }}+E_{\text {on_ half }}+E_{o f f_{-} \text {half }}+E_{\text {on_ Diode_ half }}+E_{\text {rec_ }} \text { half }\right)
$$

where $I_{C}\left(t_{i}\right)$ and $T_{T_{-} i}$ are the average current and the conduction time of the IGBT conduction of the $i$-th working state; $I_{C_{-} \text {on }}\left(t_{i}\right)$ and $I_{C_{-} \text {off }}\left(t_{i}\right)$ are the collector currents of IGBT turn-on and turn-off time of the $i$-th working state, $I_{F}\left(t_{i}\right)$ and $T_{D_{-} i}$ is the average current and the conduction time of the diode conduction of the $i$-th working state, and $\mathrm{m}$ is the ratio of the carrier frequency to the modulation wave frequency.

The RC-IGBT loss calculation is similar to that of the conventional IGBT, including IGBT switching loss and conduction loss, diode conduction loss, and reverse recovery loss [24]. The calculation of the IGBT switching loss and conduction loss for RC-IGBT is as the same as that for conventional IGBT, without considering if the RC-IGBT worked under RCDC or not. The calculation of the diode loss of RC-IGBT under saturation control is consistent with that of the conventional IGBT diode. Under the diode desaturation control, the calculation method is similar, but the selected parameters are different according to the desaturation pulse. The loss difference between the RC-IGBT under the desaturation control and the RC-IGBT under the saturation control (the conventional IGBT) is analyzed as following. During a switching period, the difference of the IGBT turn-on loss is defined as $\Delta E_{\text {on }}$, the conducting loss and the turn-off loss are the same (constant, if the conventional IGBT), the difference of the diode conduction loss is defined as $\Delta E_{\text {on_diode, }}$ and the difference of the diode reverse recovery loss is defined as $\Delta E_{\text {rec }}$. Under the two control conditions, the total loss variation of RC-IGBT, $\Delta E_{t o t}$ can be expressed as:

$$
\Delta E_{\text {tot }}=\Delta E_{\text {on }}+\Delta E_{\text {on_diode }}+\Delta E_{\text {rec }}+\text { const }
$$

For the convenience of calculation, the duty cycle is set 0.5 , the theoretical turn-on time of the diode is half of the switching period. IGBT turn-on loss actually includes the loss caused by normal turn-on current and the loss that is caused by the superposed reverse recovery current of the corresponding diode. Under the two control conditions, the turn-on loss variation of RC-IGBT, $\Delta E_{t o t}$ can be expressed as:

$$
\Delta E_{o n}=\frac{1}{2} \beta V_{C E} \cdot I_{R M} \cdot t_{r r}-\frac{1}{6} \beta V_{C E} \cdot I_{R M} \cdot \frac{t_{r r}{ }^{2}}{t_{o n}}-\frac{1}{6}\left(2 \beta-\beta^{2}\right) V_{C E} \cdot I_{R M} \cdot \frac{t_{r r} t_{A}}{t_{o n}}
$$

where $t_{o n}$ is the turn-on time of RC-IGBT, the reverse recovery time is $t_{r r}=t_{A}+t_{B}, t_{A}$, and $t_{B}$ are corresponding to the rise time and the fall recovery time, $I_{R M}$ is the peak current of the diode reverse 
recovery, $I_{C}$ is the collector current, $V_{C E}$ is the DC voltage, and $\beta$ is the influence coefficient with the desaturation pulse, which is only related to the peak current of the diode reverse recovery, the rise time and the fall recovery time.

Under the two control conditions, the diode reverse recovery loss variation of RC-IGBT, $\Delta E_{\text {rec }}$ can be expressed as:

$$
\Delta E_{r e c}=\frac{1}{6} \beta V_{C E} \cdot I_{R M} \cdot t_{r r}+\frac{1}{6}\left(2 \beta-\beta^{2}\right) V_{C E} \cdot I_{R M} \cdot t_{A}
$$

The diode conduction loss under the desaturation control is less than that of the saturation control. Under the two control conditions, the diode conduction loss variation of RC-IGBT, $\Delta E_{\text {rec }}$ can be expressed as:

$$
\Delta E_{\text {rec }}=\Delta V_{F} \cdot I_{C} \cdot\left(t_{\text {diode }} \text { on }-t_{\text {des }}\right)
$$

where $\Delta V_{F}$ is the difference of the diode conduction voltages under the two control conditions with different gate voltages, $t_{\text {des }}$ is the desaturation pulse width, and $t_{\text {diode_on }}$ is the diode conduction time.

\subsection{Pulse Timing of PWM Converter with RC-IGBT}

Figure 5 is the main circuit structure of the single-phase voltage-source PWM converter. $T_{1} \sim T_{4}$ are full controlled devices, $L_{m}$ and $R_{m}$ are, respectively, an inductance and equivalent resistance of the $\mathrm{AC}$ side, and $C_{d}$ is a capacitor of the DC side. In addition, $u_{s}$ and $i_{s}$ are the grid voltage and current, and $u_{a b}$ and $u_{d c}$ are the AC side voltage and the DC output voltage, respectively [25].

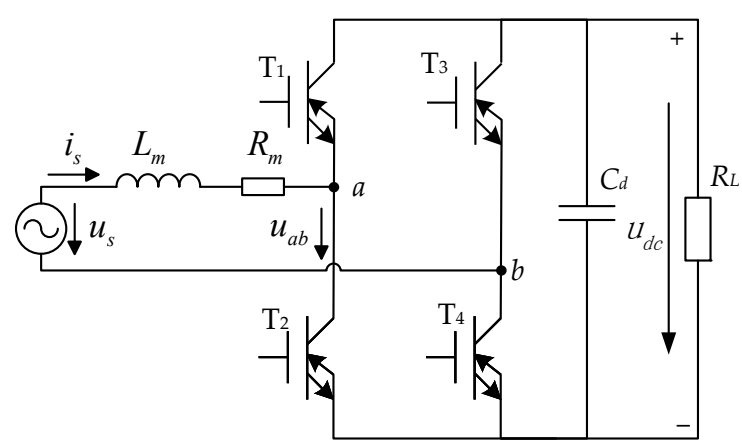

Figure 5. Main circuit structure of single-phase voltage-source pulse width modulation (PWM) converter with RC-IGBT.

In the implementation of energy exchange, the direction of the current of the DC voltage source flowing into the DC circuit and the direction of the DC voltage connecting to the AC side, namely the PWM converter in the converter or inverter working conditions, depending on the states of four switches in the main circuit [26]. With the traction condition as an example, Table 1 gives eight working states of the desaturation pulse logic of the single-phase PWM converter. "Conventional pulse" represents four PWM pulses of a conventional PWM converter, and "desaturation pulse" represents four pulses of an RC-IGBT PWM converter. For example, "0110" means that the gate voltages of switches 2 and 3 are high, and the gate voltages of switches 1 and 4 are low. The desaturation pulse logic of RC-IGBT saturation at each state switching point is also given in the table. For example, " 3 to 1 " means switching from state 3 to state 1 , and the $T_{2}$ turns on and the $T_{1}$ is reverse recovery. At the same time, the $T_{1}$ is applied with a desaturation pulse.

According to the working mode of the PWM converter with RC-IGBT gate desaturation control, Figure 6 shows the desaturation control process of the single-phase PWM converter in the traction condition. The solid line boxes represent the alternating work processes of the rectification working mode and the power supply short circuit mode, while the dashed boxes represent the alternating work processes of the inverter working mode and the power short circuit mode. The letters on the arrow represent the devices, which need to be desaturated in the corresponding working mode. At this point, 
a desaturation pulse is applied depending on the direction of the inductor current and the state of the switch on the opposite side. The letters around the digits correspond to devices in the diode mode that need to be applied to the low drive voltage. The operating states 4 to 5 and the working states 8 to 1 will lead to an inductance current zero crossing. In other words, the full devices will switch from diode mode to IGBT mode. In addition, the desaturation control process of the PWM converter in the regenerative condition is similar to that in the traction condition.

Table 1. Timing of desaturation pulse for RC-IGBT in different working states.

\begin{tabular}{|c|c|c|c|c|}
\hline$u_{\mathrm{s}}$ & State & Conventional Pulse & Desaturation Pulse & Conducting Switches \\
\hline \multirow{6}{*}{$>0$} & 1 & 0110 & 0110 & $\mathrm{~T}_{\text {2-IGBT }}, \mathrm{T}_{\text {3-IGBT }}$ \\
\hline & 2 & 0101 & 0100 & $\mathrm{~T}_{2 \text {-IGBT }}, \mathrm{T}_{4-\mathrm{DIODE}}$ \\
\hline & 3 & 1010 & 0010 & $\mathrm{~T}_{1 \text {-DIODE }}, \mathrm{T}_{3 \text {-IGBT }}$ \\
\hline & 4 & 1001 & 0000 & $\mathrm{~T}_{1 \text {-DIODE }}, \mathrm{T}_{4 \text {-DIODE }}$ \\
\hline & $\begin{array}{l}3 \rightarrow 1 \\
4 \rightarrow 2\end{array}$ & \multicolumn{2}{|c|}{$\mathrm{T}_{1}$ desaturated } & $\begin{array}{c}\mathrm{T}_{2} \text { turned on } \\
\mathrm{T}_{1} \text { reverse recovery }\end{array}$ \\
\hline & $\begin{array}{l}2 \rightarrow 1 \\
4 \rightarrow 3\end{array}$ & \multicolumn{2}{|c|}{$\mathrm{T}_{4}$ desaturated } & $\begin{array}{c}\mathrm{T}_{3} \text { turned on } \\
\mathrm{T}_{4} \text { reverse recovery }\end{array}$ \\
\hline \multirow{6}{*}{$<0$} & 5 & 1001 & 1001 & $\mathrm{~T}_{1-\mathrm{IGBT}}, \mathrm{T}_{4-\mathrm{IGBT}}$ \\
\hline & 6 & 1010 & 1000 & $\mathrm{~T}_{1 \text {-IGBT, }} \mathrm{T}_{3 \text {-DIODE }}$ \\
\hline & 7 & 0101 & 0001 & $\mathrm{~T}_{2 \text {-DIODE }}, \mathrm{T}_{4 \text {-IGBT }}$ \\
\hline & 8 & 0110 & 0000 & $\mathrm{~T}_{2 \text {-DIODE }}, \mathrm{T}_{3 \text {-DIODE }}$ \\
\hline & $\begin{array}{l}7 \rightarrow 5 \\
8 \rightarrow 6\end{array}$ & \multicolumn{2}{|c|}{$\mathrm{T}_{2}$ desaturated } & $\begin{array}{c}\mathrm{T}_{1} \text { turned on } \\
\mathrm{T}_{2} \text { reverse recovery }\end{array}$ \\
\hline & $\begin{array}{l}6 \rightarrow 5 \\
8 \rightarrow 7\end{array}$ & \multicolumn{2}{|c|}{$\mathrm{T}_{3}$ desaturated } & $\begin{array}{c}\mathrm{T}_{4} \text { turned on } \\
\mathrm{T}_{3} \text { reverse recovery }\end{array}$ \\
\hline
\end{tabular}

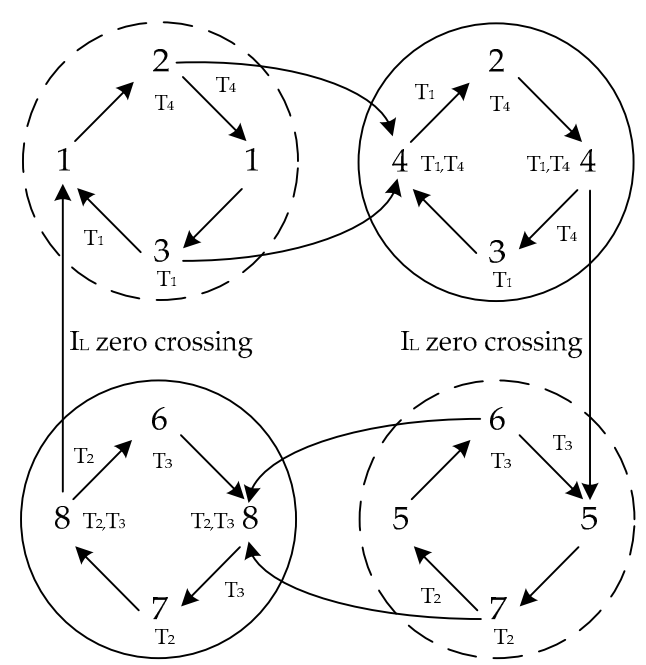

Figure 6. Process of the desaturation control of single-phase PWM converter in traction.

\section{Loss Threshold Desaturation Control of RC-IGBT PWM Converter}

\subsection{Improved Predictive Current Control}

Based on the predictive current control of conventional PWM converter and the criterion of inductance current, an improved predictive current control for the PWM converter, which is suitable for the RC-IGBT is obtained [27-31]. The conventional single-phase PWM converter is controlled by the predictive current method. In a PWM period, the inductance current satisfies the following equation:

$$
i_{s}\left(t_{k}+T_{s}\right)=i^{*}{ }_{s}\left(t_{k}\right)
$$


According to the analysis of the circuit topology, the following equation is established:

$$
\begin{aligned}
& u^{*}{ }_{a b}=u_{s}-R_{m} i_{s}-\frac{L_{m}\left(i^{*}{ }_{s}-i_{s}\right)}{T_{s}} \\
& I^{*}{ }_{s}=K_{\mathrm{p}}\left(U^{*}{ }_{d c}-u_{d c}\right)+1 / T_{i} \int\left(U^{*}{ }_{d c}-u_{d c}\right) d t \\
& u_{a b}(t)=u_{s}(t)-\frac{L_{s}}{T_{s}}\left[I^{*}{ }_{s} \sin \omega t-i_{s}(t)\right]
\end{aligned}
$$

The four channels' voltage generated by the PWM generator is processed by the logic of desaturation. The relations of the gate voltages are described as Formulas (16) and (17). $u_{g e \_d e s 1}(t) \sim u_{g e \_d e s}(t)$ are the four gate voltages after desaturation. The $\varepsilon(t)$ is the step function. While the current is positive, $\varepsilon\left[i_{s}(t)\right]=1$, and the current is reverse, $\varepsilon\left[i_{s}(t)\right]=0 . f_{\text {delay }}$ and $f_{\text {des }}$ are the delay function and the desaturation processing function, respectively.

$$
\begin{aligned}
& {\left[\begin{array}{l}
u_{g e \_d e s}(t) \\
u_{g e \_d e s}(t)
\end{array}\right]=\left\{1-\varepsilon\left[i_{s}(t)\right]\right\} * f_{\text {delay }}\left[\begin{array}{l}
u_{g e 1}(t) \\
u_{g e 4}(t)
\end{array}\right]+\varepsilon\left[i_{s}(t)\right] * f_{\text {des }}\left[\begin{array}{l}
u_{g e 1}(t) \\
u_{g e 4}(t)
\end{array}\right]} \\
& {\left[\begin{array}{l}
u_{g e \_d e s}(t) \\
u_{g e \_d e s}(t)
\end{array}\right]=\varepsilon\left[i_{s}(t)\right] * f_{\text {delay }}\left[\begin{array}{l}
u_{g e 2}(t) \\
u_{g e 3}(t)
\end{array}\right]+\left\{1-\varepsilon\left[i_{s}(t)\right]\right\} * f_{\text {des }}\left[\begin{array}{l}
u_{g e 2}(t) \\
u_{g e 3}(t)
\end{array}\right]}
\end{aligned}
$$

According to the above equations, the following control charts in Figure 7 are obtained:

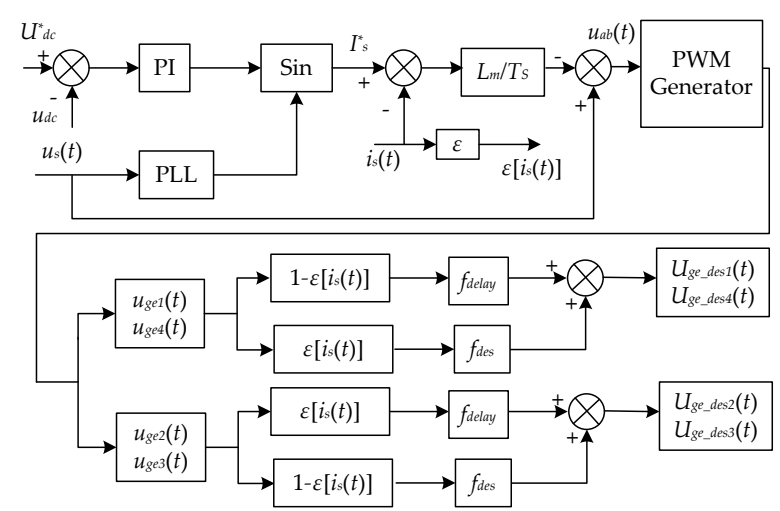

Figure 7. Control block diagram of the improved predictive current control.

From the analysis of every state of the PWM rectifier in Section 2.2, provided that the direction of the inductor current is determined, the working mode of each bridge arm can be accurately judged. Figure 8 shows the logic diagram of the desaturation pulse control of the PWM converter with RC-IGBT.

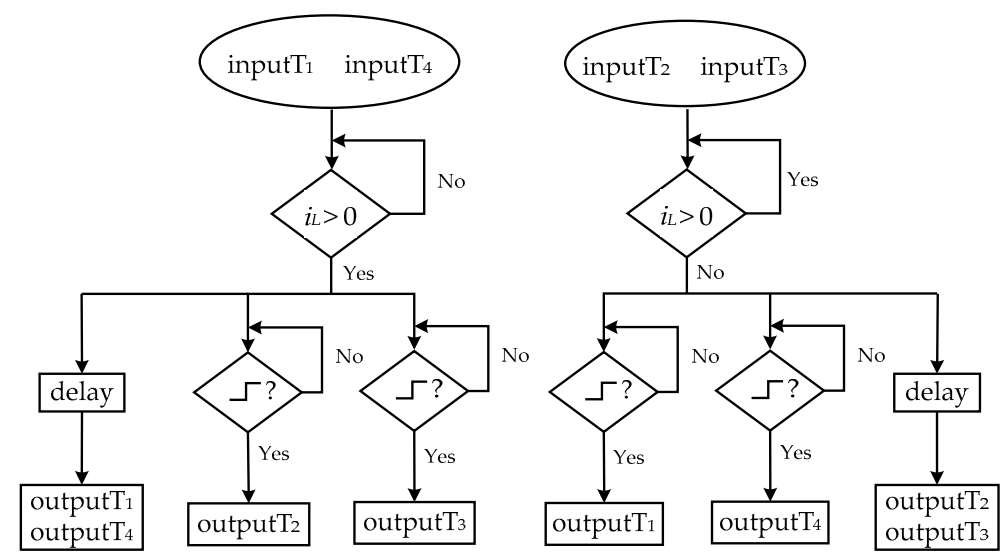

Figure 8. Logic diagram of the desaturation pulse control of the PWM converter with RC-IGBT. 
The inputs $T_{1}, T_{2}, T_{3}$, and $T_{4}$ in Figure 8 are four conventional input signals with a dead time of $5 \mu \mathrm{s}$, and the inductor current, $i_{L}$, is also an input. The four output signals are outputs $\mathrm{T}_{1}, \mathrm{~T}_{2}, \mathrm{~T}_{3}$, and $\mathrm{T}_{4}$. The direction of the input current $i_{L}$ is judged firstly. When its direction is forward, the pulse generations of the $T_{1}$ and $T_{2}$ are analyzed together. Because the $T_{1}$ has been in diode mode in this process, the driving voltage of the $T_{1}$ should be low. In addition to meeting the needs of the gate of the RC-IGBT in diode mode that is applied to the low voltage, the desaturation pulse must also be imposed to reduce the diode reverse recovery loss. Importantly, the rising edge of input $\mathrm{T}_{2}$ should be detected, the output $T_{1}$ is obtained by the desaturation pulse procedure of input $T_{2}$. At the same time, the output $\mathrm{T}_{2}$ can also be obtained by delaying the input $\mathrm{T}_{2}$ for the time $t_{\text {delay }}$. Similarly, the pulse generations of $T_{3}$ and $T_{4}$ are based on the desaturation pulse procedure and the delay of input $T_{4}$. The process of the reverse input current is treated similarly.

\subsection{Desaturation Control of Loss Decrement Threshold}

In the improved predictive current control strategy with the desaturation pulse for the single-phase PWM converter, the value and direction of the inductor current are the key to RCDC control, and directly affect the working and loss characteristics of RC-IGBT. When compared to the operation at saturation mode, the loss of RC-IGBT in the RCDC control decreases. In a given modulation period, the performance of the RCDC control is closely related to the loss variation. When considering the shock of the inductor current error in zero crossing, as well as the error of the sensor detection, the RCDC control in the small current condition will lead to a mutation in the time sequence of the desaturation pulse, which in turn, may cause the bridge arm to short circuit, and pulse blockade and greater harmonic. In addition, the loss variation of the RCDC control is not obvious under the small current condition. In order to reduce the fault risk that is caused by the triggering of the desaturation pulse, and to utilize the loss suppression of large current conditions, a desaturation control scheme based on the loss decrement threshold per-unit value is proposed. According to the scheme, as compared to the RC-IGBT saturation control, the loss decrement of RC-IGBT in the RCDC control is changed little near the zero crossing of the current. The loss decrement changes largely in the moment, thus the working current is great. By setting the threshold of the loss decrement per-unit value corresponding a small current value, the RCDC control is executed when the actual per-unit value of the loss decrement is below the threshold, and is not executed when it exceeds the threshold.

We set the threshold of the loss decrement per-unit value equal to $\Delta \mathrm{E}_{\mathrm{th}}{ }^{*}$, when the actual per-unit value of the loss decrement is less than or equal to $\Delta \mathrm{E}_{\mathrm{th}}{ }^{*}$, the inductor current is corresponding to $\left[-I_{L m a x},-I_{L t h}\right]$ and $\left[I_{L t h}, I_{L m a x}\right]$, and the RCDC control is performed. When the actual per-unit value of the loss decrement is greater than $\Delta \mathrm{E}_{\mathrm{th}}{ }^{*}$, then the inductor current is corresponding to [ $\left.-\mathrm{I}_{\mathrm{Lth}}, \mathrm{I}_{\mathrm{Lth}}\right]$ and the RCDC control is not performed. $\mathrm{I}_{\mathrm{Lmax}}$ is the peak value of the inductor current, and $\mathrm{I}_{\mathrm{Lth}}$ is the current threshold corresponding to the loss threshold. Figure 9 shows the logic block diagram of the desaturation control for the threshold of the loss decrement per-unit value corresponding to the inductance current zero-crossing threshold value.

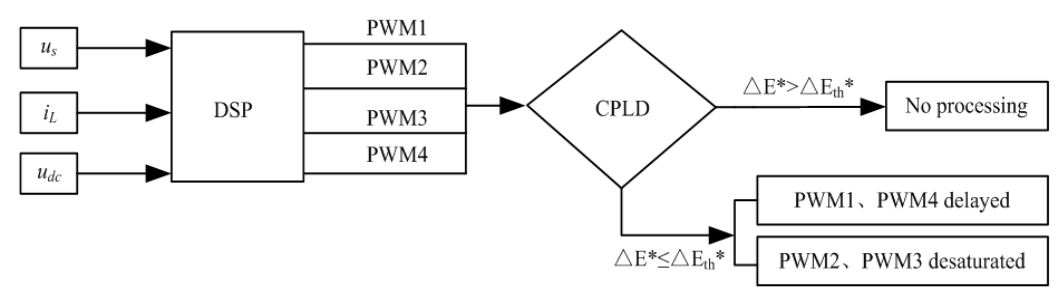

Figure 9. Logic block diagram of the desaturation control for the threshold of the loss decrement per-unit value.

For the selection of the loss threshold decrement per-unit value, one should refer to the specific environment in which the device is applied and the working current flowing through it. When the 
device is operating within the rated current range, the $10 \%$ peak current is selected as the current threshold $\mathrm{I}_{\text {Lth. }}$.

\section{Simulation and Experiment}

\subsection{Simulation Analysis}

In order to verify the feasibility of the desaturation pulse control in the PWM converter with conventional IGBT, the simulation model was built in Matlab Simulink 8.6, R2015B (MathWorks, Natick, MA, USA). The controller adopted a double closed loop approach that was based on the improved predictive current control. The Table 2 shows the simulation parameters of the main circuit originated from the design parameters of the locomotive four quadrant converter of China Railway High-speed 2 (CRH2):

Table 2. Design parameters of locomotive four quadrant converter of China Railway High-speed 2 (CRH2).

\begin{tabular}{ccc}
\hline Parameter Name & Signal & Value \\
\hline AC side rated voltage & $U_{N}$ & $1950 \mathrm{~V}$ \\
AC side rated frequency & $f_{N}$ & $50 \mathrm{~Hz}$ \\
DC side output voltage & $U_{d}$ & $3500 \mathrm{~V}$ \\
Operating frequency & $f_{S}$ & $450 \mathrm{~Hz}$ \\
AC side inductance & $L_{m}$ & $2.195 \mathrm{mH}$ \\
AC side resistor & $R_{m}$ & $0.01 \Omega$ \\
DC side support capacitance & $C_{d}$ & $5 \mathrm{mF}$ \\
Filter inductance & $L_{2}$ & $1.27 \mathrm{mH}$ \\
Filter capacitance & $C_{2}$ & $2 \mathrm{mF}$ \\
Load resistor & $R$ & $8.75 \Omega$ \\
\hline
\end{tabular}

Figure 10 shows the models of the predictive current control of the conventional IGBT PWM rectifier and the improved predictive current control with desaturation pulses of the RC-IGBT PWM rectifier under the same simulation parameters.

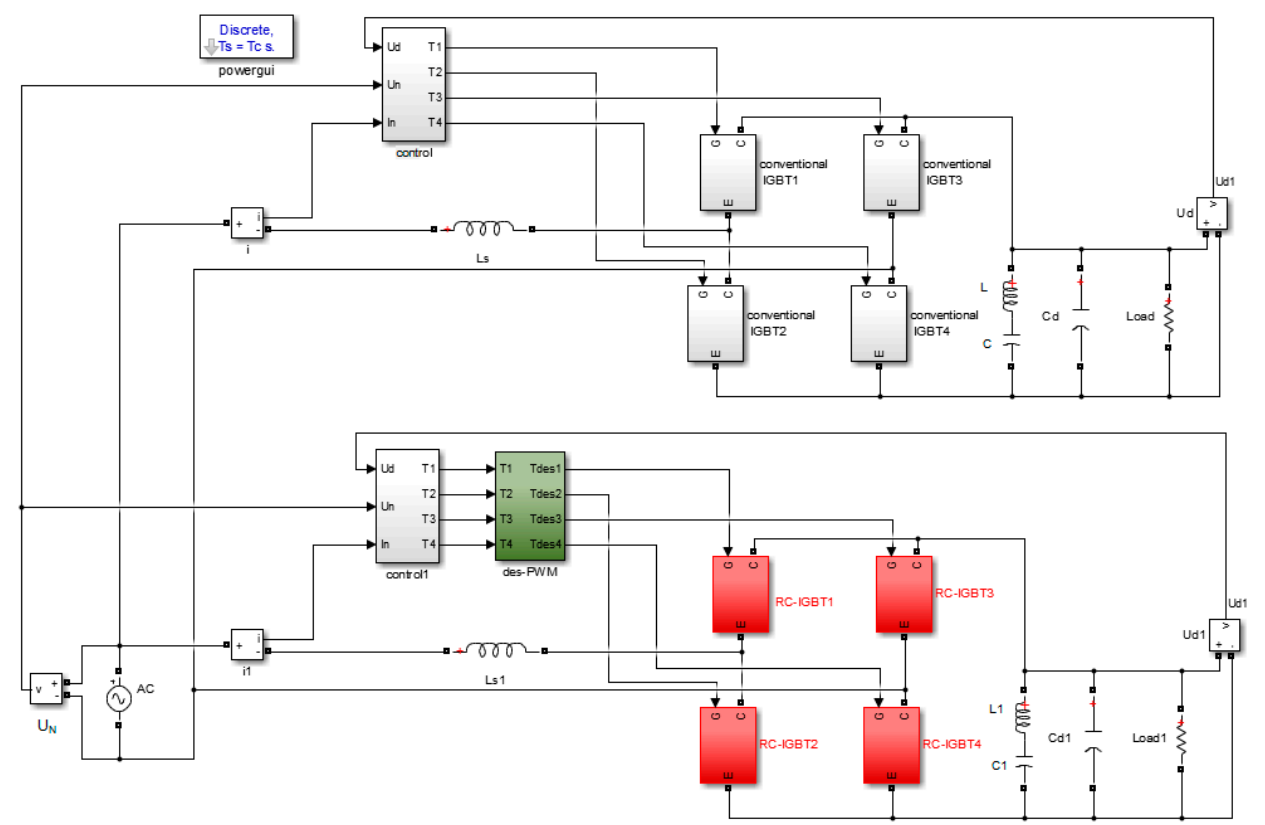

Figure 10. The simulation circuit of the single-phase PWM rectifier under saturation control and desaturation control. 
The simulation results are shown in Figure 11. The output voltage $u_{d c}$, the grid voltage $u_{s}$ and the inductor current $i_{s}$ are shown under different operations: (a) the conventional IGBT PWM rectifier; (b) the RC-IGBT PWM rectifier under the desaturation control of the current threshold 10\%; and, (c) the RC-IGBT PWM rectifier under the all period desaturation control. It can be seen from the diagram that the three control methods can all ensure the DC output stable at $3500 \mathrm{~V}$. The voltage and current of the grid keep synchronous, using fast Fourier transformation (FFT) analysis, the grid current total harmonic distortion (THDs) are 2.02\% under saturation control, $2.01 \%$ under desaturation control of the current threshold $15 \%$, and $2.01 \%$ under all period desaturation control. The system works stably in the rectifier state.

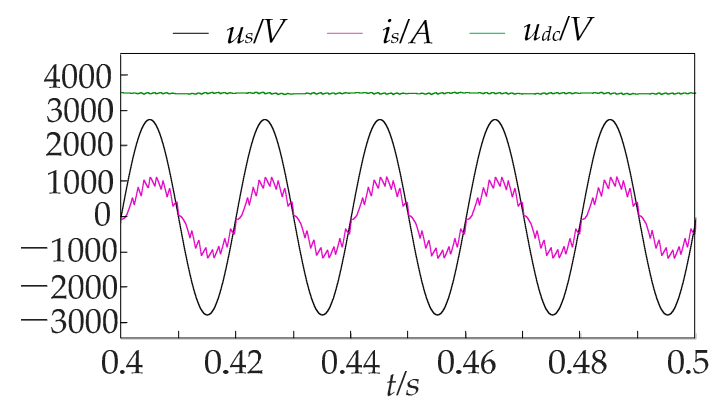

(a)

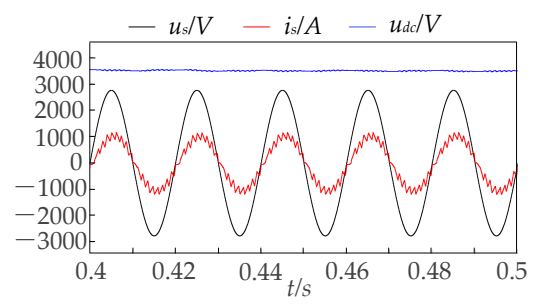

(b)

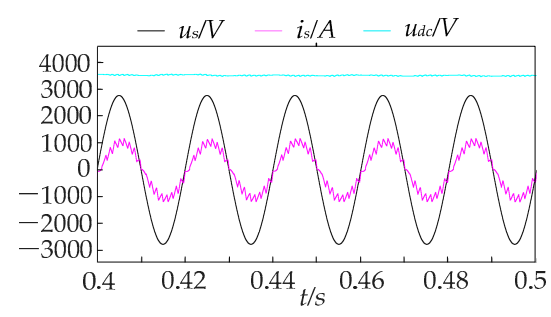

(c)

Figure 11. Steady-state waveforms: output voltage $u_{d c}$, grid voltage $u_{s}$ and the inductor current $i_{S}$ under (a) conventional IGBT; (b) all period desaturation control; (c) desaturation control of the current threshold $10 \%$.

According to the simulation, the average current value of the device in a switching cycle could be calculated. Referring to the device parameter manual, the total loss of a modulation cycle under rated conditions can be calculated. The following Table 3 shows the loss data of the four conditions: conventional IGBT, RC-IGBT saturation control, RC-IGBT current threshold desaturation control, and RC-IGBT full cycle desaturation control. Due to the different characteristics of the conventional IGBT, all of the partial loss and the total loss of the desaturation controlled RC-IGBT are decreased. The IGBT turn-on loss, the diode conduction loss and reverse recovery loss of the RC-IGBT under saturation control are increased. Additionally, there is no difference in the total loss between the desaturation control of the current threshold $10 \%$ and the whole cycle desaturation control.

As shown in Figure 12, the partial loss and the total loss of the system are compared under different loads. When compared to the conventional IGBT, the total loss of RC-IGBT single-phase PWM rectifier under the saturation control increases by about 5.2\% under three different loads, respectively. The total loss of RC-IGBT single-phase PWM rectifier under all of the period desaturation control decreases by $11.7 \%$ under the rated load, $10.8 \%$ under the half load, and $12.5 \%$ under the 1.5 times load. In other words, under the condition of a large load and high load current, the loss of the RC-IGBT under the desaturation control decreased more significantly. When the current threshold is different, the loss suppression is different. So it is necessary to adjust the setting according to the actual working conditions. 
Table 3. Datasheet of loss for conventional insulated gate bipolar transistor (IGBT) and RC-IGBT PWM converters.

\begin{tabular}{|c|c|c|c|c|c|c|}
\hline PWM Converter & $E_{\text {con_IGBT }} / \mathrm{mJ}$ & $E_{o n} / \mathrm{mJ}$ & $E_{o f f} / \mathrm{mJ}$ & $E_{\text {on_diode }} / \mathrm{mJ}$ & $E_{r e c} / \mathrm{mJ}$ & $E_{t o t} / \mathrm{mJ}$ \\
\hline Con-IGBT *1 & 3520 & 24,160 & 15,680 & 11,950 & 13,040 & 68,350 \\
\hline RC-IGBT(SAT) $* 2$ & 3420 & 26,880 & 15,620 & 12,510 & 13,480 & 71,910 \\
\hline RC-IGBT $($ RCDC $) * 3$ & 3420 & 17,340 & 15,620 & 11,510 & 12,430 & 60,320 \\
\hline RC-IGBT(THDC) $* 4$ & 3420 & 17,500 & 15,620 & 11,590 & 12,590 & 60,520 \\
\hline
\end{tabular}

Note: ${ }^{* 1}$ expresses conventional IGBT; ${ }^{* 2}$ expresses RC-IGBT saturation control (SAT); ${ }^{* 3}$ expresses RC-IGBT all period desaturation control; ${ }^{* 4}$ expresses RC-IGBT desaturation control of the current threshold (THDC) $10 \%$.

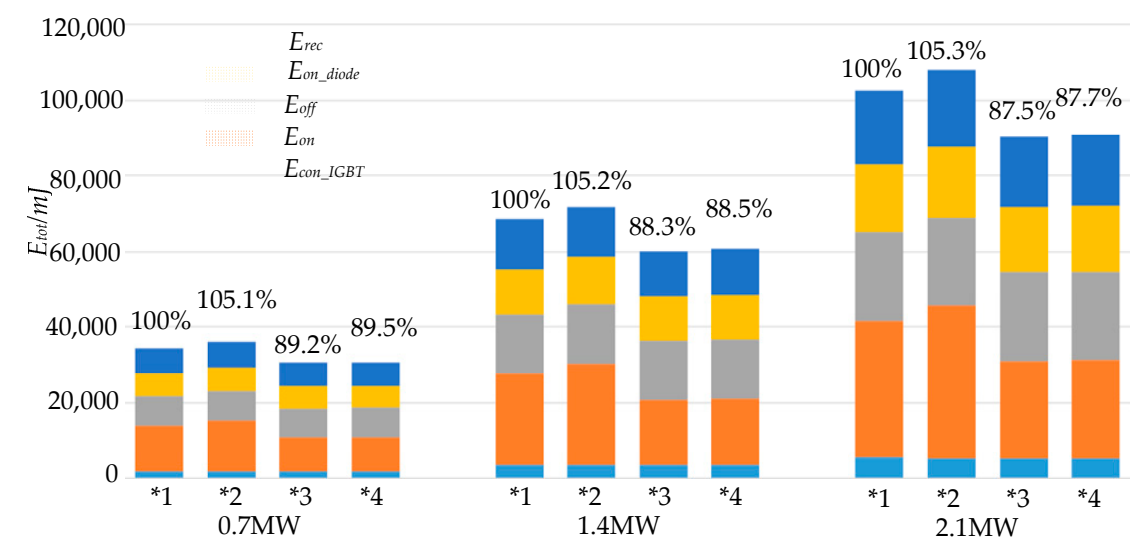

Figure 12. Total loss comparison between conventional IGBT and RC-IGBT at different loads. (Note: PWM Converters under four type conditions ${ }^{* 1},{ }^{* 2}, * 3$ and ${ }^{* 4}$ in Figure 12 are corresponding to those of Table 3).

By changing the current threshold, the single-phase PWM converter is simulated under different load currents, and the average loss in the positive half cycle is calculated. Table 4 shows that the load current $\mathrm{I}_{\mathrm{L}}$ was, respectively, $0.2,0.5,0.8$, and $1.5 \mathrm{I}_{\mathrm{N}}$, the percentage of the current threshold $\mathrm{I}_{\mathrm{PU}}$ (the ratio of the current threshold to the peak current) was equal to zero (complete judgment on zero-crossing), 0.1 to $0.8,1$ (saturation control), the average loss decrement per-unit value in the half cycle is $\Delta \mathrm{E}^{*}$ (the ratio of the difference of the average loss between the saturation control and desaturation control to saturation control). The $\mathrm{I}_{\mathrm{N}}$ is $500 \mathrm{~A}$.

Table 4. Average loss decrement per-unit value in half cycle of single-phase PWM converter under different current thresholds and different load currents.

\begin{tabular}{ccccccccccc}
\hline $\mathbf{I}_{\mathbf{L}} \backslash \mathbf{I}_{\mathbf{P U}}$ & $\mathbf{0}$ & $\mathbf{1 0} \%$ & $\mathbf{2 0} \%$ & $\mathbf{3 0} \%$ & $\mathbf{4 0} \%$ & $\mathbf{5 0} \%$ & $\mathbf{6 0} \%$ & $\mathbf{7 0} \%$ & $\mathbf{8 0} \%$ & $\mathbf{1}$ \\
\hline $0.2 \mathrm{I}_{\mathrm{N}}$ & 0.1400 & 0.1317 & 0.1080 & 0.0894 & 0.0867 & 0.0834 & 0.0795 & 0.0603 & 0.0516 & 0 \\
$0.5 \mathrm{I}_{\mathrm{N}}$ & 0.1513 & 0.1437 & 0.1319 & 0.1205 & 0.1177 & 0.1119 & 0.1040 & 0.0764 & 0.0608 & 0 \\
$0.8 \mathrm{I}_{\mathrm{N}}$ & 0.1545 & 0.1506 & 0.1459 & 0.1343 & 0.1211 & 0.1212 & 0.1155 & 0.0820 & 0.0625 & 0 \\
$\mathrm{I}_{\mathrm{N}}$ & 0.1606 & 0.1544 & 0.1493 & 0.1384 & 0.1332 & 0.1238 & 0.1207 & 0.0868 & 0.0681 & 0 \\
$1.5 \mathrm{I}_{\mathrm{N}}$ & 0.1690 & 0.1619 & 0.1515 & 0.1396 & 0.1338 & 0.1261 & 0.1233 & 0.0859 & 0.0669 & 0 \\
\hline
\end{tabular}

By using the MATLAB three spline interpolation to set up the binary relation among $\mathrm{I}_{\mathrm{L}}, \mathrm{I}_{\mathrm{PU}}$ and $\Delta E^{*}$, the three-diensional (3D) graphs of which are shown in Figure 13. When the $\mathrm{I}_{\mathrm{PU}}$ is less than 0.1, the $\Delta \mathrm{E}^{*}$ does not change significantly; when the $\mathrm{I}_{\mathrm{PU}}$ is higher than 0.1 , with the decrease of $\mathrm{I}_{\mathrm{PU}}$, the $\Delta \mathrm{E}^{*}$ increases significantly. Taking the rated load as an example, when the $\mathrm{I}_{\mathrm{PU}}$ is 0.1 , the maximum value 0.16 of $\Delta \mathrm{E}^{*}$ is obtained. When considering repeatability and small current low loss characteristics near the zero current of the load current, the optimal graph of the loss decrement of the PWM converter is drawn, namely $\mathrm{I}_{\mathrm{PU}} 10 \%$, the curve of $\Delta \mathrm{E}^{*}$ and $\mathrm{I}_{\mathrm{L}}$. In addition, Figure 13 also shows the curve of $\Delta \mathrm{E}^{*}$ and $\mathrm{I}_{\mathrm{PU}}$ when $\mathrm{I}_{\mathrm{L}}$ is $\mathrm{I}_{\mathrm{N}}$. The intersection point of the two curves is the best working point of RC-IGBT single-phase PWM rectifier under rated conditions. 


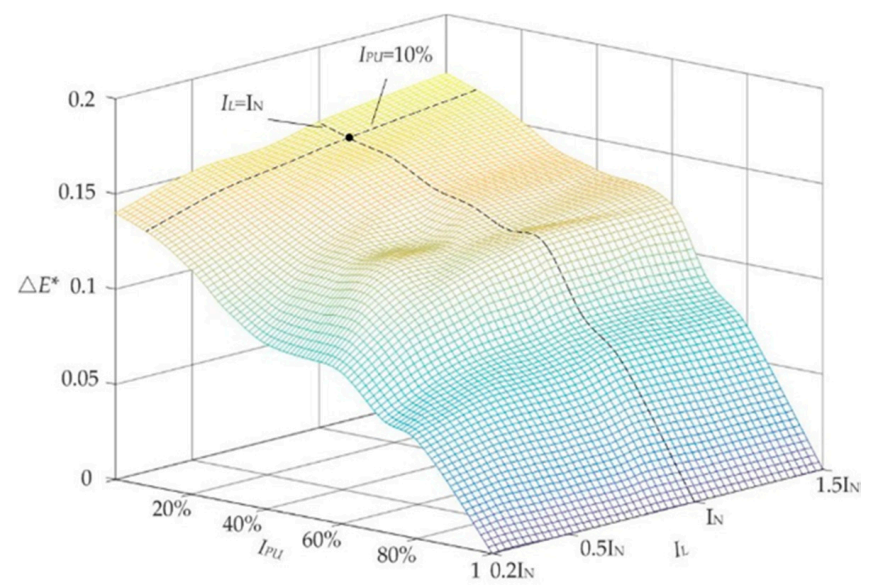

Figure 13. Surface graph of the variety of average loss decrement per unit value with load current and current threshold percentage.

\subsection{Experimental Results}

In order to further verify the design method above, the experimental study is carried out. The grid voltage is reduced by the voltage regulator to $195 \mathrm{~V}$ from $220 \mathrm{~V}$. The experimental parameters are $U_{s}=195 \mathrm{~V}, f_{N}=50 \mathrm{~Hz}, U_{d}{ }^{*}=350 \mathrm{~V}$, and switching frequency $f_{S}=1 \mathrm{kHz}$. The PWM converter model is made up of a half bridge switching devices for Infineon FZ1000R65KR3, and another half bridge for Infineon FZ750R65KE3 [32]. The inductance $L_{m}$ is $12.8 \mathrm{mH}$ and the capacitors are two parallel and two series capacitors, namely $470 \mu \mathrm{F} / 450 \mathrm{~V}$. The digital signal processing (DSP) in the controller is Texas Instruments (TI) TMS320LF28335 (Texas Instruments (TI), Dallas, TX, USA), to mainly achieve the improved current predictive control algorithm, and the complex programmable logic device (CPLD) is ALTERA's EPM7128AETC100-7 (Altera, Silicon Valley, CA, USA) to realize the desaturation control algorithm. Figure 14 shows the test platform.

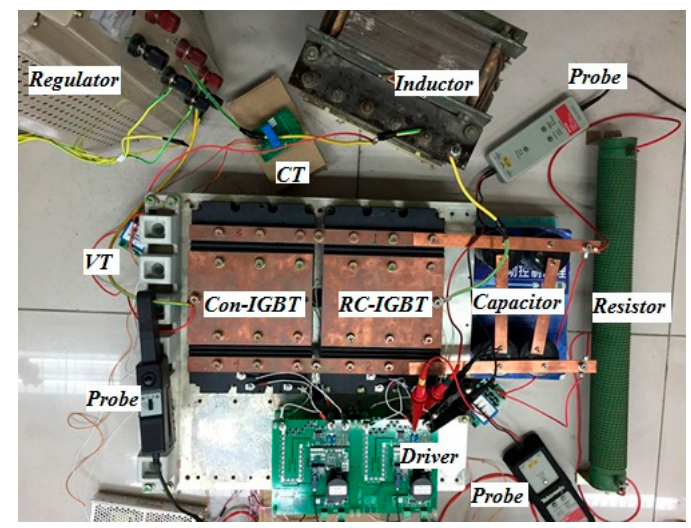

Figure 14. Test platform for RC-IGBT PWM convertor.

The steady state experimental waveform PWM converter is under saturation control and all period desaturation control. As shown in Figure 15, the output voltage $u_{d c}$ under conventional control is about $350 \mathrm{~V}$, which is 1.79 times the grid voltage, and the ripple voltage is small. Although the switching frequency is low, the AC side current waveform is still close to the sinusoidal waveform, with a power factor equal to 1 . At the same time, under saturation control, the output voltage and output current waveform of the PWM converter are almost the same as those under saturation control. Through the grid side current waveform data are analyzed by the MATLAB FFT function, the THD of the gird side current is $4.76 \%$ under saturation control. Those of desaturation pulse width $50 \mu$ sare 
$4.60 \%$ under all period desaturation control. The results prove that the desaturation control is effective and feasible.

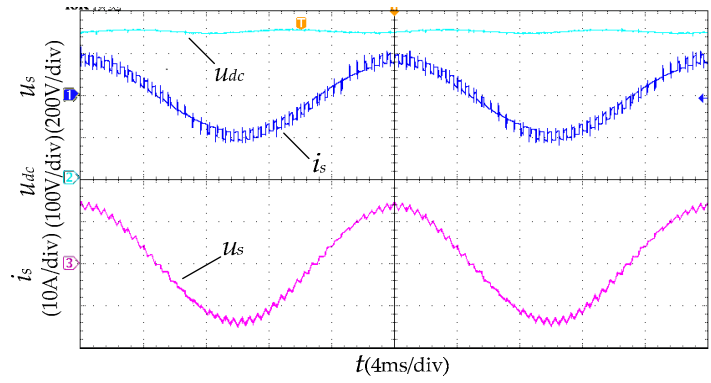

(a)

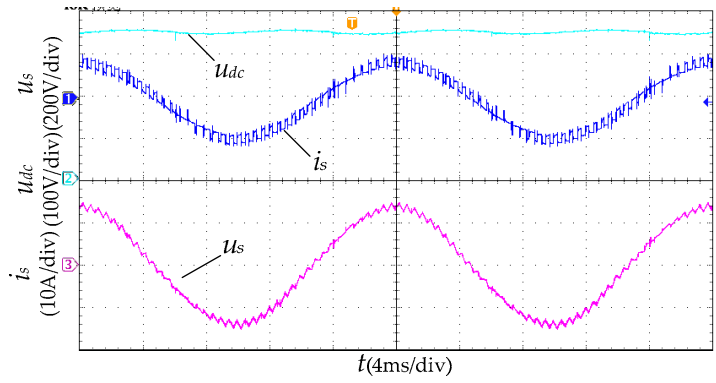

(b)

Figure 15. Steady-state experimental waveforms: the grid voltage $u_{s}$, output voltage $u_{d c}$ and grid current $i_{s}$, (a) saturation control, THD $=4.76 \%$; (b) all period desaturation control, $t_{\text {desat }}=50 \mu \mathrm{s}, t_{\text {lock }}=3 \mu \mathrm{s}$, THD $=4.60 \%$.

Figure 16 compares the gate voltage waveforms of $T_{1}$ and $T_{2}$ under saturation control and all period desaturation control. It can be seen from Figure $16 \mathrm{~b}$ that $\mathrm{T}_{1}$ is desaturated and the gate pulse of $\mathrm{T}_{2}$ is unchanged under desaturation control when the grid current is positive. When the grid current is reverse, $T_{2}$ is desaturated and the gate pulse of $T_{1}$ is unchanged.

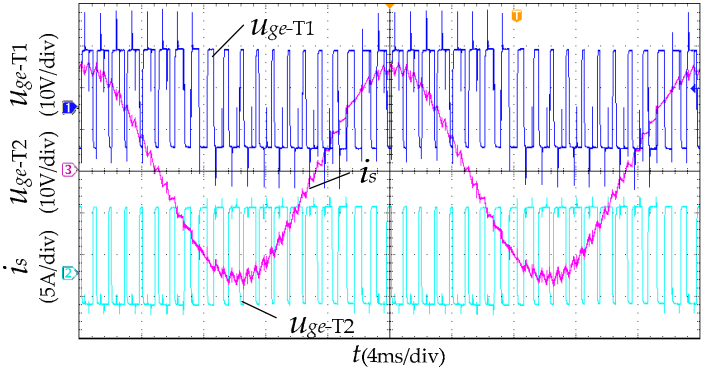

(a)

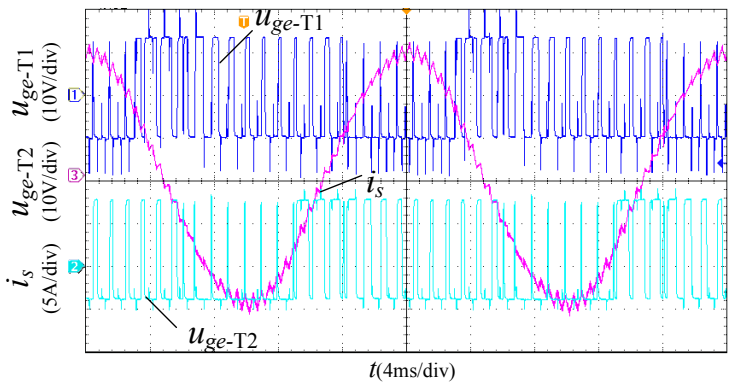

(b)

Figure 16. Steady-state experimental waveforms: the gate voltages $u_{g e}$ of the $\mathrm{T}_{1}$ and $\mathrm{T}_{2}$ and the inductor current, (a) saturation control; (b) all period desaturation control, $t_{\text {desat }}=50 \mu \mathrm{s}, t_{\text {lock }}=3 \mu \mathrm{s}$.

Figure 17 is an enlargement of the positive half period of the current in Figure 17b. The gate level of the $T_{1}$ has a short pulse before gate voltage of the $T_{2}$ is high every time, i.e., the desaturation pulse. Figure 17a shows that the desaturation pulse width of $50 \mu \mathrm{s}$, and Figure 17b shows the interlock time of $3 \mu \mathrm{s}$. Therefore, the experimental parameters are completely consistent with those in the theoretical design.

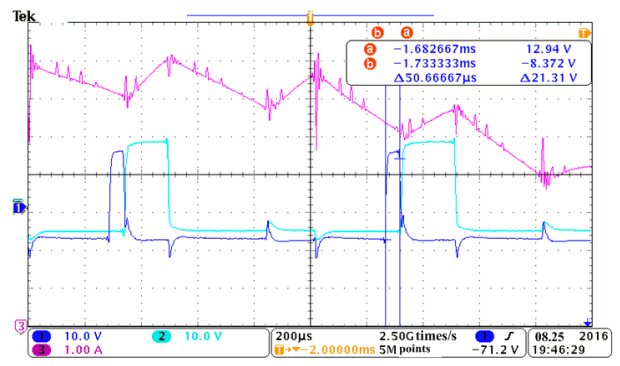

(a)

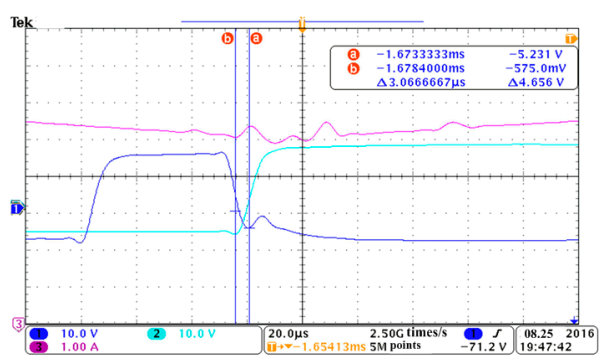

(b)

Figure 17. Parameters under desaturation control: (a) desaturation pulse width $50 \mu$ s; (b) lock time $3 \mu$ s. 
Figure 18 shows the gate voltage waveforms of $T_{1}$ and $T_{2}$ under the condition of (a) the current threshold $=2$ A corresponding to a loss decrement threshold per-unit value of 0.13 , (b) the current threshold $=10$ A corresponding to a loss decrement threshold per-unit value of 0.08 , and (c) the current threshold $=13 \mathrm{~A}$ corresponding to a loss decrement threshold per-unit value of 0.05 . The greater the current threshold is, then the shorter the desaturation times of $\mathrm{T}_{1}$ and $\mathrm{T}_{2}$ will be. The PWM converters can all work steadily under the different current thresholds. As the threshold current increases, the loss decrement threshold per-unit value gradually decreases. Figure 18a is the waveform of the condition that has the best loss characteristics.

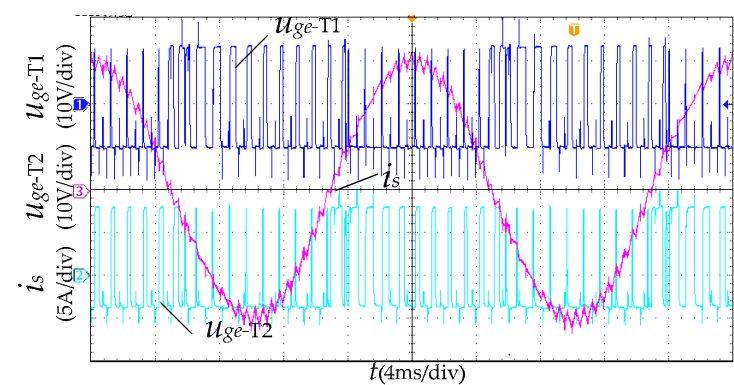

(a)

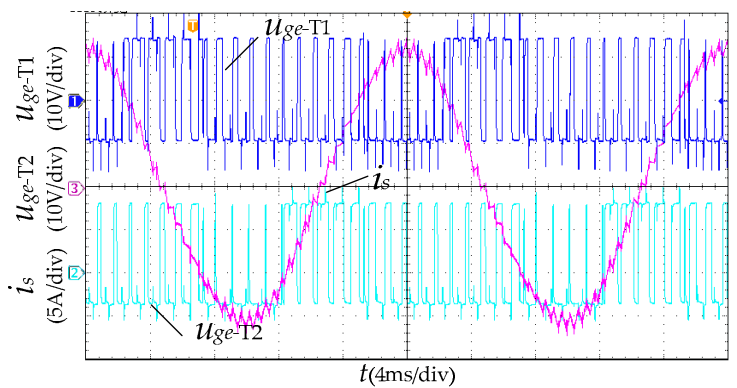

(b)

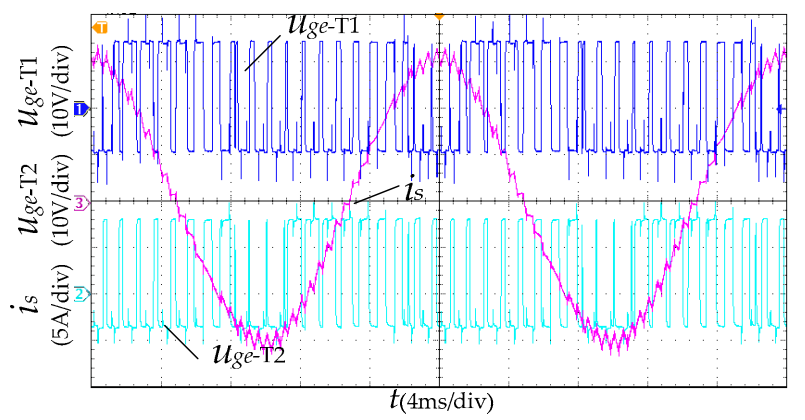

(c)

Figure 18. Steady-state experimental waveforms under different loss thresholds: (a) $I_{\text {th }}=2$ A, $\Delta \mathrm{E}^{*}=0.13 ;(\mathbf{b}) \mathrm{I}_{\mathrm{th}}=10 \mathrm{~A}, \Delta \mathrm{E}^{*}=0.08 ;(\mathbf{c}) \mathrm{I}_{\mathrm{th}}=13 \mathrm{~A}, \Delta \mathrm{E}^{*}=0.05$.

\section{Conclusions}

Due to the fact that it has its own low thermal resistance and high current density, the RC-IGBT satisfied the high capacity single-phase PWM converter requirements, namely high power density and reliability. In this paper, the gate desaturation control of the diode integrated in the RC-IGBT is studied and the desaturation control of switching devices of the full bridge circuit is realized. The improved predictive current control of the PWM converter is studied. The loss decrement threshold desaturation control method applied to the RC-IGBT single-phase PWM converter is proposed. In order to avoid the desaturation pulse chaos in the current zero crossing, by setting the loss decrement threshold to limit the current threshold corresponding to the desaturation pulse applied to RC-IGBT, the operating performance of the PWM converter in low switching frequency is improved. Finally, the modeling and simulation of the PWM converter of the RC-IGBT are completed, and the simulation results confirm the effectiveness of the desaturation control. Experiments are carried out on a small power experiment platform to verify the effectiveness of the control strategy.

Acknowledgments: In this paper, the samples and test data are recorded with the strong support of Toshiba and Infineon Beijing Co. We wish to express our heartfelt thanks to them. The research is also supported by "the Fundamental Research Funds for the Central University (2017JBM061)". 
Author Contributions: Xianjin Huang and Trillion Q. Zheng conceived and designed the experiments; Dengwei Chang and Chao Ling performed the experiments; Xianjin Huang analyzed the data; Trillion Q. Zheng contributed materials and analysis tools; Xianjin Huang wrote the paper.

Conflicts of Interest: The authors declare no conflict of interest.

\section{References}

1. Wen, J.P. Research on the Control Strategies of Single-Phase Three-Level Pwm Rectifier; Beijing Jiaotong University: Beijing, China, 2012; pp. 1-96.

2. Song, K.J. Research and Implementation of Three Phase Current Source Rectifier; Nanjing University of Aeronautics and Astronautics: Nanjing, China, 2014; pp. 1-99.

3. Liu, B. Constant-Frequency-Hysteresis Control Strategy for Single Phase PWM Rectifiers; Southwest Jiaotong University: Chengdu, China, 2016; pp. 1-75.

4. Zhang, Y.C.; Peng, Y.B.; Qu, C.Q. Predictive current control of PWM rectifier under unbalanced grid voltage condition. Trans. China Electrotech. Soc. 2016, 31, 88-94.

5. Song, W.S.; Deng, Z.X. Model predictive power control scheme for single-phase PWM rectifiers with constant switching frequency. Electr. Mach. Control 2016, 20, 93-100.

6. Yin, K.; Ma, M.Y.; Cao, M.H.; He, Y.M.; Deng, Y.; Hen, X.N. Research on three-phase hybrid-clamped five-level PWM rectifier. Proc. CSEE 2012, 32, 59-66.

7. Huang, H. The Research of Single-Phase PWM Rectifier and Control Strategy; Huazhong University of Science \& Technology: Wuhan, China, 2012; pp. 1-66.

8. Yang, L.Y.; Yang, S.; Zhang, W.P.; Chen, Z.G.; Long, X.U. An improved deadbeat predictive current control method for single-phase PWM rectifiers. Proc. CSEE 2015, 35, 5842-5850.

9. Deng, Z.X.; Song, W.S.; Cao, M.H. A model predictive current control scheme for single-phase PWM rectifiers. Proc. CSEE 2016, 36, 2992-3004.

10. Wei-Zhong, C.; Ze-Hong, L.; Bo, Z.; Min, R.; Jin-Ping, Z.; Yong, L.; Zhao-Ji, L. A snapback suppressed reverse-conducting IGBT with uniform temperature distribution. Chin. Phys. B 2014, 23, 513-518.

11. Qiu, H. T-Type Three-Level Inverter with Reverse Blocking IGBT; Beijing Jiaotong University: Beijing, China, 2015; pp. 1-80.

12. Li, X.P.; Liu, J.; Cao, G.; Gao, M.C.; Wang, Y.H.; Jin, R.; Wen, J.L. Development and application of reverse conducting-IGBT in smart grid. Smart Grid 2017, 5, 1-8.

13. Mitsubishi Datasheet: CM1000HG-130XA IGBT Module Data Sheet; Mitsubishi Electric Corporation: Tokyo, Japan, 2017.

14. Huang, X.J.; Ling, C.; Sun, H.; You, X.J.; Xiao, C.J. Working characteristics of Reverse-Conducting IGBT applied in vehicle converters. Semiconduct. Technol. 2017, 5, 363-370.

15. Fock-Sui-Too, J.L.; Chauchat, B.; Nicolau, S.; Madrid, F.; Austin, P.; Tounsi, P.; Mermet-Guyennet, M. Experimental study of power IGBT technologies at large range temperature. In Proceedings of the International Conference on Mixed Design of Integrated Circuits and Systems IET, Poznan, Poland, 19-21 June 2008; pp. 519-524.

16. Chen, W.Z. Theoretical Model and Novel Structures for RC-IGBT; University of Electronic Science and Technology of China: Chengdu, China, 2014; pp. 1-94.

17. Zhu, L.H. Study on Novel Reverse-Conducting IGBT; University of Electronic Science and Technology of China: Chengdu, China, 2014; pp. 1-101.

18. Werber, D.; Pfirsch, F.; Gutt, T.; Komarnitskyy, V.; Schaeffer, C.; Hunger, T.; Domes, D. 6.5 kV RCDC: For increased power density in IGBT-modules. In Proceedings of the IEEE International Symposium on Power Semiconductor Devices \& IC's, Waikoloa, HI, USA, 15-19 June 2014; pp. 35-38.

19. Werber, D.; Hunger, T.; Wissen, M.; Schuetze, T. A 1000 A $6.5 \mathrm{kV}$ power module enabled by reverse-conducting trench-IGBT-technology. In Proceedings of the International Exhibition and Conference for Power Electronics, Intelligent Motion, Renewable Energy and Energy Management (PCIM), Shanghai, China, 28-30 June 2016; pp. 351-358.

20. Huang, X.J.; Ling, C.; Chang, D.W.; You, X.J.; Zheng, T.Q. Loss characteristics of 6.5kV RC-IGBT applied to a traction converter. Energies 2017, 10, 891. [CrossRef] 
21. Eckel, H.; Wigger, D. Comparison of the output power of RC-IGBT and IGBT/diode inverters. In Proceedings of the Preliminary Conference Program PCIM Europe 2011, Nuremberg, Germany, 17-19 May 2011; pp. 38-43.

22. Hermann, R.; Krafft, E.U.; Marz, A. Reverse-conducting-IGBTs-A new IGBT technology setting new benchmarks in traction converters. In Proceedings of the IEEE European Conference on Power Electronics and Applications, Lille, France, 2-6 September 2013; pp. 1-8.

23. Huang, X.J.; You, X.J.; Zheng, Q.L. Traction converter with desaturated diode control for reverse conducting IGBT. Trans. China Electrotech. Soc. 2016, 31 (Suppl. 2), 58-66.

24. Zhang, Z.R.; Xu, Z.; Xue, Y.L. Valve losses evaluation based on piecewise analytical method for MMC-HVDC links. IEEE Trans. Power Deliv. 2014, 29, 1354-1362. [CrossRef]

25. Liu, Z.G. Power Electronics; Tsinghua University Press; Beijing University Press: Beijing, China, 2004; pp. $182-191$.

26. Du, X.H. Modeling and Characteristic Research of High Power IGBTs Applied in Traction; Beijing Jiaotong University: Beijing, China, 2016; pp. 1-75.

27. Zhang, Y.; Liu, J. An improved model-free predictive current control of PWM rectifiers. In Proceedings of the 2017 20th International Conference on Electrical Machines and Systems (ICEMS), Sydney, Australia, 11-14 August 2017; pp. 1-5.

28. Kwak, S.; Kim, S.E.; Park, J.C. Predictive current control methods with reduced current errors and ripples for single-phase voltage source inverters. IEEE Trans. Ind. Inform. 2015, 5, 1006-1016. [CrossRef]

29. Luo, Y.; Liu, C.; Yu, F. Predictive current control of a new three-phase voltage source inverter with phase shift compensation. IET Electr. Power Appl. 2017, 5, 740-748. [CrossRef]

30. Garcia, C.F.; Rivera, M.E.; Rodríguez, J.R.; Wheeler, P.W.; Peña, R.S. Predictive current control with instantaneous reactive power minimization for a four-Leg indirect matrix converter. IEEE Trans. Ind. Electron. 2017, 2, 922-929. [CrossRef]

31. Liu, Y.C.; Ge, X.; Tang, Q.; Deng, Z.; Gou, B. Model predictive current control for four-switch three-phase rectifiers in balanced grids. Electron. Lett. 2017, 1, 44-46. [CrossRef]

32. Dütemeyer, T.; Schütze, T. Mitsubishi Datasheet: FZ750R65KE3 IGBT Module Data Sheet; Infineon Corporation: Munich, Germany, 2009.

(C) 2017 by the authors. Licensee MDPI, Basel, Switzerland. This article is an open access article distributed under the terms and conditions of the Creative Commons Attribution (CC BY) license (http:/ / creativecommons.org/licenses/by/4.0/). 